\title{
Necessity and conditionality regarding the electromagnetic track brake - parametric study
}

\author{
Cătălin Cruceanu* and Camil Crăciun \\ University Politehnica of Bucharest, Department of Railway Vehicles, 313 Splaiul Independenţei, \\ 060042, Bucharest, Romania
}

\begin{abstract}
The paper explores the speed limits requiring additional braking systems independent of rail/wheel adhesion. Regarding the electromagnetic track brake (MTB), conditions to achieve the safety traffic requirements for stopping distances and decelerations are investigated by means of numerical simulations. The computing program integrates the movement equation of the vehicle, taking into account weight, resistance to forward movement, etc. The study is performed for $40 \ldots 60 \mathrm{t}$ four axles passenger vehicles and it was considered a speed domain of $160 \ldots 300$ $\mathrm{km} / \mathrm{h}$. The results indicate that deceleration requirements are an important limitative parameter for constructive top speeds of railway vehicles. For velocities higher than $210 \ldots 230 \mathrm{~km} / \mathrm{h}$, the braking distances exceed the possibility of running under conventional signalling system.
\end{abstract}

\section{Introduction}

Increased tonnages and speeds in railway transport put more pressure on braking systems, as equipment directly connected to traffic safety. Given the importance, the requirements related to train braking are carefully and clear stated by regulations. Train braking is a highly complex process, depending on numerous operational, technical and constructive factors and, especially in case of passenger vehicles, a delicate balance between traffic safety requirements, track, signalling system and comfort must be achieved [1-4]. Specific for railway vehicles, the classical pneumatic UIC type main brake system is wheel/rail adhesion dependent [4-6]. This particularity restricts the maximum braking force, while safety requirements are generally connected to a limited stopping distance consistent with the signalling system. Increasing top speeds in passenger traffic require additional braking systems (e.g. MTBs, eddy current linear systems) that are independent of wheel/rail adhesion and therefore able to develop supplementary force to meet the safety conditions. One must also take into account that the passengers must not be submitted to very high decelerations. Nevertheless, the energy to be dissipated in a relatively short time influence the thermal regime, while the rapid wear of the braking system friction elements led to the development of dynamic-type systems, such as electric or eddy current braking systems. Anyway, MTBs and eddy current brakes induce potential disturbing effects of on track circuits, axle counters etc.

\footnotetext{
*Corresponding author: c_cruceanu@yahoo.com
} 
Accordingly, in high speed domain, an assembly of multiple braking systems is used, coordinated in an optimal way to take full advantage of the benefits of each one.

The present study is targeted on MTB system, commonly in use with disc brakes in order to increase the braking capacity. It is a parametric study based on simulations focused on the stopping distances, maximum and average decelerations achieved during emergency braking actions performed by $40 \ldots 60$ t passenger vehicles in a top speeds range of $160 \ldots$ $300 \mathrm{~km} / \mathrm{h}$. The aim is to highlight the top speed limits of the disc brake system and the necessity of MTBs for higher velocities, as well as constrains and operational conditions in accordance to safety and comfort recommendations.

\section{Theoretical aspects}

For a vehicle having a mass $m$, running on a straight uninclined track and submitted to a total braking force $F_{b}$, considering $x$ the distance covered, the equation of movement is:

$$
F_{b}(t, \dot{x})+m \cdot g \cdot w_{m}\left(t, \dot{x}, \dot{x}^{2}\right)=\rho \cdot m \cdot \ddot{x}
$$

Where $w_{m}$ is the specific resistance to forward movement, $\rho$ the higher than one mass factor accounting the inertia of the rotating masses and $g$ the gravitational acceleration.

According to specific particularities, the retardation force due to the disc brake system is directly depending on the actual air pressure within the brake cylinders $p_{b c}(t)$ and, taking into account the limitation due to the wheel/rail adhesion, can be determined [6-8]:

$$
F_{D}\left(p_{b c}\right)=m \cdot g \cdot \mu_{a}\left(V_{\max }\right) \frac{p_{b c}}{p_{\max }}
$$

Where $V_{\max }[\mathrm{km} / \mathrm{h}]$ is the constructive top speed of the vehicle, $\mu_{a}$ the adhesion coefficient and $p_{\max }$ the maximum air pressure in brake cylinders during the emergency braking action.

As additional braking system, MTBs in use on railway vehicles are mounted on the bogie frame between the wheels, in line with the centre of the rail. When lowered to contact the rail, a magnetic clamping force is developed by the current passing through a coil wrapped around the pole pieces and the friction between the MTBs and the rail creates a retardation force which is independent of wheel/rail adhesion. This is the main advantage, as it creates the possibility of increasing the braking force of the main braking system, essential for the traffic safety when running with higher speeds. Constructively, the high suspension solution for MTB is preferred: a $60-130 \mathrm{~mm}$ clearance is maintained between the brake shoes and rails and the activation is by air cylinders.

Considering $N_{e m}$ as total electromagnetic attraction force/vehicle and $\mu_{M T B}$ the friction coefficient between shoes and rails, the MTB braking force is:

$$
F_{M T B}(V)=N_{e m} \cdot \mu_{M B T}(V)
$$

Given the specific increase of the friction coefficient between shoes and rails with the decrease of the velocity $V$ of the railway vehicle, in order to avoid excessive decelerations, the action of MTB, actuated only during emergency braking, must automatically become ineffective as soon as the speed falls below a certain limit. Braking power provisions refer to a limitation in the stopping distance, generally depending on the signalling system, and/or in decelerations which should not exceed certain levels, in order to avoid affecting the passengers comfort. In the situation of combined use of disc brakes and MTB, the total braking force is:

$$
F_{b}=F_{D}+F_{M T B}
$$


Considering functional and operational particularities, qualitative evolution of braking forces during emergency braking and correspondent decelerations are presented in Figure 1.

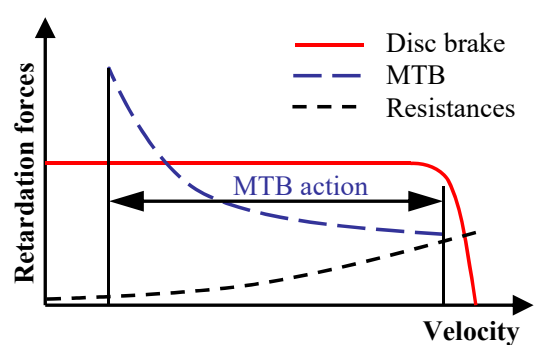

a. Retardation forces

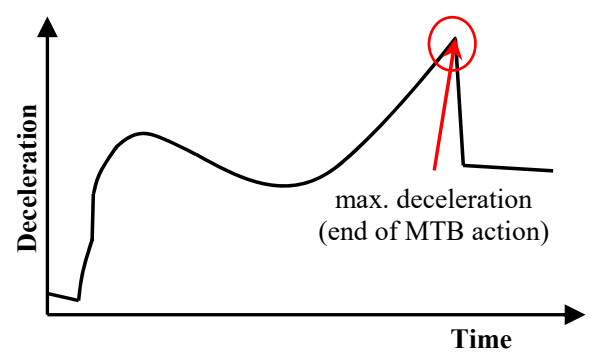

b. Deceleration

Fig. 1. Qualitative evolution of retardation forces and decelerations during emergency braking action.

\section{Numeric simulations}

For numeric simulations, a computing program has been elaborated in MATLAB in order to integrate the movement equation (1). There are options for combination of usual braking systems. Pneumatic data regarding the particularities of UIC main system are supported either as experimental acquisitioned data, or as interpolation functions. Graphic facilities are available for results. In the present study, numerical simulations refer to four axles passenger vehicles equipped basically with disc brakes, designed for top speeds in the range of $160-300 \mathrm{~km} / \mathrm{h}$. The interest was focused on the braking distances, maximum and average decelerations for disc brake system only or in combination with MTB.

\subsection{Main input data}

The main specific resistances (see eq. 1) were considered:

$$
w_{m}(V)=1.65+V^{2} / 4000
$$

The friction coefficient between MTB shoes and rail (see eq. 3) was considered:

$$
\begin{gathered}
\mu_{m b}(V) \cong 5.12 \cdot 10^{-15} V^{6}+2.37 \cdot 10^{-12} V^{5}+4.09 \cdot 10^{-10} V^{4}-1.23 \cdot 10^{-7} V^{3}+ \\
+4.37 \cdot 10^{-5} V^{2}-6.75 \cdot 10^{-3} V+0.47
\end{gathered}
$$

Based on acquisitioned data regarding the air pressure pbc evolution in brake cylinders for UIC type pneumatic brake with KE $1 \mathrm{~b}$ distributor, there were determined the maximum air pressure 3.805 bars, the filling time $3.36 \mathrm{~s}$ and the duration of achieving 0.4 bars is 0.54 s. Determined by interpolation, the analytical equations describing the process are:

$$
p_{b c}(t)=\left\{\begin{array}{c}
0.015 t^{6}-0.027 t^{5}-0.271 t^{4}+1.132 t^{3}-1.132 t^{2}+2.31 t+0.395 \\
\text { if } t \in[0,3] \\
0.798 t^{4}-1.842 t^{3}+0.761 t^{2}+0.736 t+3.343, \text { if } t \in(3,4] \\
3.805, \text { if } t>4 \mathrm{~s}
\end{array}\right.
$$

Regarding MTB, it was assumed that the brake shoes apply in $3 \mathrm{~s}$ following the braking command and become ineffective for less than a threshold running speed $\mathrm{Vi}$. 
Considering the operational particularities of the investigated systems and the wheel/rail adhesion coefficient $\mu_{\mathrm{a}}=0.33 /\left(1+0.011 \cdot \mathrm{V}_{\mathrm{max}}\right)$, the braking force during the whole process is assumed as follows:

$$
F_{b}\left(t, p_{b c}, V\right)=\left\{\begin{array}{c}
0, \text { for } t \leq 0.54 \mathrm{~s} \\
m \cdot g \cdot \mu_{a}\left(V_{\text {max }}\right) \cdot \frac{p_{b c}}{p_{\max }}, \text { for } t \in(0.54,3] \\
m \cdot g \cdot \mu_{a}\left(V_{\text {max }}\right) \cdot \frac{p_{b c}}{p_{\text {max }}}+N_{e m} \cdot \mu_{M B T}(V), \text { for } t \in(3,4] \\
m \cdot g \cdot \mu_{a}\left(V_{\text {max }}\right)+N_{e m} \cdot \mu_{M B T}(V), \text { for } t>4 \text { s and } V \geq V_{i} \\
m \cdot g \cdot \mu_{a}\left(V_{\text {max }}\right), \text { for } V \in\left(V_{i}, 0\right]
\end{array}\right.
$$

According the aim of study, simulations were carried out in three successive stages, the role, purpose and main threshold values for each of them are summarized in Table 1.

Table 1. Outline of numeric simulations stages.

\begin{tabular}{|c|c|c|c|}
\hline \multicolumn{4}{|c|}{ Stage 1 - speed limits for use of disc brake system only } \\
\hline main input data & output data & conditions & ongoing results \\
\hline $\begin{array}{l}\text { top speed range } 160-300 \\
\mathrm{~km} / \mathrm{h} \\
\text { mass range } 40-60 \mathrm{t}\end{array}$ & $\begin{array}{l}\text { braking distance } s_{b} \\
\text { brake force } F_{b} \\
\text { adhesion force } F_{a} \\
\text { max. deceleration } a_{M} \\
\text { average deceleration } a_{m}\end{array}$ & $\begin{array}{l}s_{b} \leq 1200 \mathrm{~m} \\
F_{b} \leq F_{a} \\
a_{M} \leq 2.5 \mathrm{~m} / \mathrm{s}^{2} \\
a_{m} \leq 1.4 \mathrm{~m} / \mathrm{s}^{2}\end{array}$ & $\begin{array}{l}\text { top speed } V_{l} \text { beyond } \\
\text { which conditions are } \\
\text { no longer met }\end{array}$ \\
\hline \multicolumn{4}{|c|}{ Stage 2 - speed limits for use of combined disc and MTB for conventional signalling system } \\
\hline main input data & output data & conditions & ongoing results \\
\hline $\begin{array}{l}\text { top speed range } V_{l}-300 \mathrm{~km} / \mathrm{h} \\
\text { mass range } 40-60 \mathrm{t} \\
\text { ineffective magnetic brake for } \\
\text { less than } V_{i}=20 / 50 \mathrm{~km} / \mathrm{h}\end{array}$ & $\begin{array}{l}\text { magnetic force } N_{e m} \\
\text { max. deceleration } a_{M} \\
\text { average deceleration } a_{m}\end{array}$ & $\begin{array}{l}a_{M} \leq 2.5 \mathrm{~m} / \mathrm{s}^{2} \\
a_{m} \leq 1.4 \mathrm{~m} / \mathrm{s}^{2}\end{array}$ & $\begin{array}{lr}\text { top speed } & V_{2}\left(V_{i}\right) \\
\text { beyond } & \text { which } \\
\text { conditions } & \text { are no } \\
\text { longer met } & \end{array}$ \\
\hline \multicolumn{4}{|c|}{ Stage 3 -operational conditions for use of combined disc and MTB } \\
\hline main input data & output data & conditions & final results \\
\hline $\begin{array}{l}\text { top speed range } V_{2}-300 \mathrm{~km} / \mathrm{h} \\
\text { mass range } 40-60 \mathrm{t} \\
\text { ineffective magnetic brake for } \\
\text { less than } V_{i}=20 / 50 \mathrm{~km} / \mathrm{h}\end{array}$ & $\begin{array}{l}\text { magnetic force } N_{e m} \\
\text { braking distance } s_{b} \\
\text { max. deceleration } a_{M} \\
\text { average deceleration } a_{m}\end{array}$ & $\begin{array}{l}a_{M} \leq 2.5 \mathrm{~m} / \mathrm{s}^{2} \\
a_{m} \leq 1.4 \mathrm{~m} / \mathrm{s}^{2}\end{array}$ & braking distance $s_{b}$ \\
\hline
\end{tabular}

\subsection{Results and comments}

The main results are presented following the stages and targets presented in Table 1.

Considering only the brake disc system, irrespective of the mass of the vehicle, the condition of fitting into a stopping distance of $1200 \mathrm{~m}$ required by the conventional signalling system is possible up to $180 \mathrm{~km} / \mathrm{h}$, irrespective of the vehicles mass (Figure 2, a). For higher top speeds an additional system, independent of wheel/rail adhesion, becomes mandatory to cover the difference between the necessary braking force (full line) and the maximum affordable by discs (dashed lines in Figure 2, b). For top speeds exceeding 180 $\mathrm{km} / \mathrm{h}$, a stopping distance of $1200 \mathrm{~m}$ becomes possible using the combined disc brake MTB system with correspondent increase of attraction electromagnetic forces (Figure 3), but taking into account the decelerations, recommended limits are exceeded for top speeds of $210 \ldots 230 \mathrm{~km} / \mathrm{h}$ (Figure 4). To notice that the highest decelerations occur just before the MTBs become ineffective, the correspondent speed Vi having important influence (Figure 5). Lower threshold for $\mathrm{Vi}$ determines a decrease of the constructive top speed due to increased maximum decelerations. 


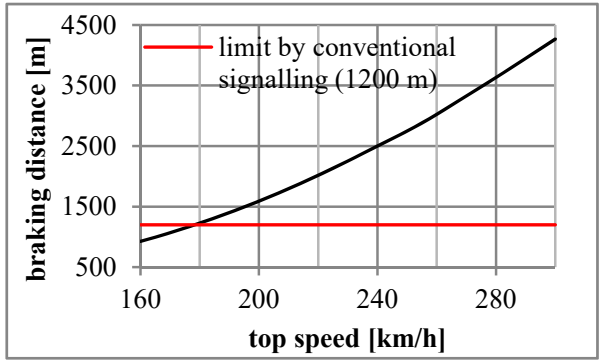

a. Stopping distance

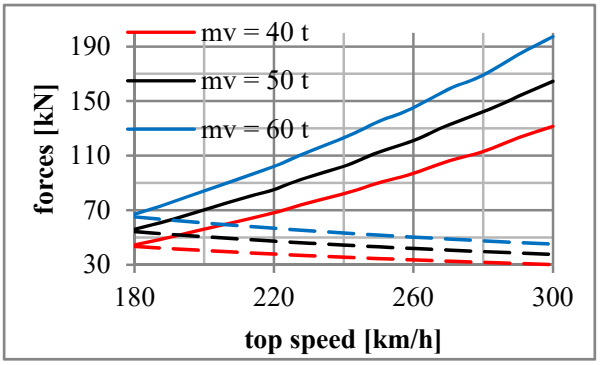

b. Braking forces and adhesion forces (dashed)

Fig. 2. Stopping distance and required braking forces for $1200 \mathrm{~m}$ brake distance (disc brake only).

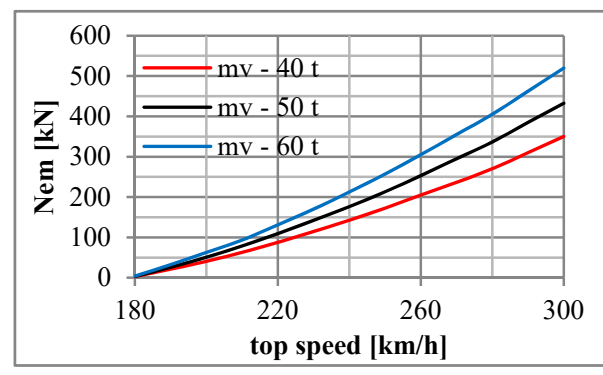

a. MTB ineffective for less than $20 \mathrm{~km} / \mathrm{h}$

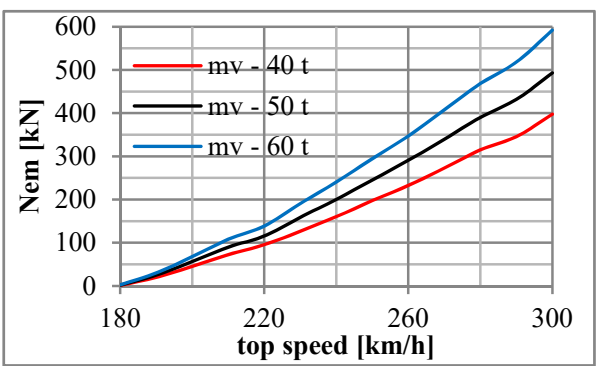

b. MTB ineffective for less than $50 \mathrm{~km} / \mathrm{h}$

Fig. 3. Attraction electromagnetic forces/MTB shoe for $1200 \mathrm{~m}$ brake distance using combined disc brake and MTB system.

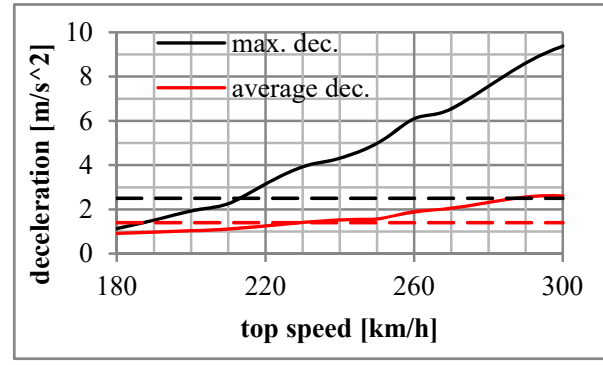

a. MTB ineffective for less than $20 \mathrm{~km} / \mathrm{h}$

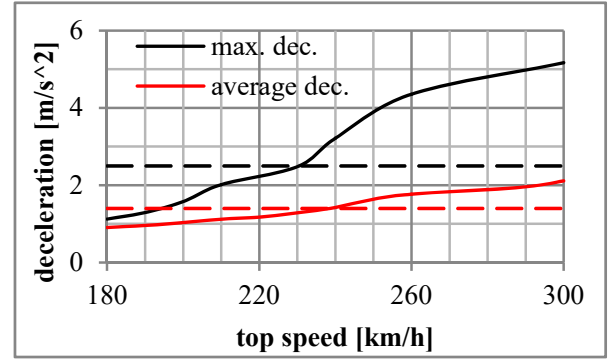

b. MTB ineffective for less than $50 \mathrm{~km} / \mathrm{h}$

Fig. 4. Decelerations for $1200 \mathrm{~m}$ brake distance using combined disc brake and MTB system (dashed lines - limits for maximal $\left(2.5 \mathrm{~m} / \mathrm{s}^{2}\right)$ and average $\left(1.4 \mathrm{~m} / \mathrm{s}^{2}\right)$ decelerations $)$.

By limiting the maximum deceleration to $2.5 \mathrm{~m} / \mathrm{s} 2$ for combined disc - MTB system, longer stopping distances must be assumed (see Figure 6). According to the mass of the vehicle $(40 \ldots 60 \mathrm{t})$, but almost irrespective of the top speed, lower attraction electromagnetic forces/MTB shoe are required: $70 \ldots 105 \mathrm{kN}$, respectively $115 \ldots 175 \mathrm{kN}$, considering that MTBs become ineffective for less than $V_{i}=20 \mathrm{~km} / \mathrm{h}$, respectively $50 \mathrm{~km} / \mathrm{h}$. In given assumptions, the average deceleration is lower than $1.3 \mathrm{~m} / \mathrm{s}^{2}$; higher speed for cutting off the effect of MTBs is more favourable and results in about $15 \%$ shorter stopping distances. These advantages are obtained by an increase in attraction electromagnetic forces (in average, about $66 \%$, irrespective of the vehicles mass, considering $20 \mathrm{~km} / \mathrm{h}$ and $50 \mathrm{~km} / \mathrm{h}$ the speed limit below which MTBs become ineffective). 


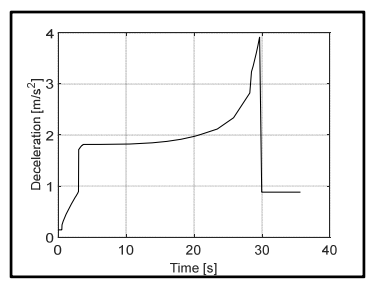

a. MTB ineffective for less than $20 \mathrm{~km} / \mathrm{h}$

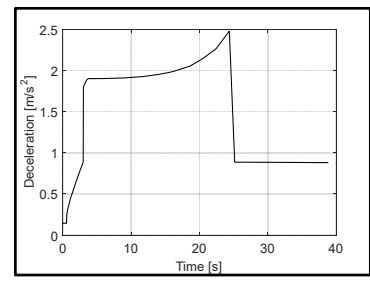

b. MTB ineffective for less than $50 \mathrm{~km} / \mathrm{h}$

Fig. 5. Decelerations for $1200 \mathrm{~m}$ brake distance using combined disc brake and MTB system (emergency braking action, top speed $-230 \mathrm{~km} / \mathrm{h}$, mass of the vehicle $-40 \mathrm{t}$ ).

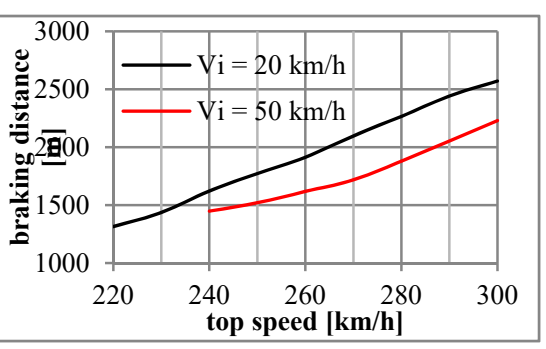

Fig. 6. Stopping distance for maximum deceleration of $2.5 \mathrm{~m} / \mathrm{s}^{2}$ using combined disc brake - MTB system.

\section{Conclusions}

Based on the results of the numeric simulations performed considering four axles classical passenger vehicles equipped with disc brakes, designed for top speeds in the range of 160 $300 \mathrm{~km} / \mathrm{h}$, according to the aim of the study, the main conclusions are outlined as follows:

- for disc brakes only, the top speed affordable by traffic safety on classical signalling tracks (brake distance limited to $1200 \mathrm{~m}$ ) is $180 \mathrm{~km} / \mathrm{h}$;

- top speeds exceeding $180 \mathrm{~km} / \mathrm{h}$ require additional braking systems independent of wheel/rail adhesion, in particular MTBs is most common solution;

- for vehicles equipped with combined disc - MTB system destined to run on classical signalling tracks, maximum deceleration of $2.5 \mathrm{~m} / \mathrm{s}^{2}$ permit top speeds of $210-230 \mathrm{~km} / \mathrm{h}$;

- top speeds exceeding above limits require longer braking distances, of $2570-2230 \mathrm{~m}$ in the assumed ranges, depending on the velocity $(20 / 50 \mathrm{~km} / \mathrm{h})$ imposed for MTBs to become ineffective.

These performances require up to $105 / 175 \mathrm{kN}$ attraction electromagnetic force/MTB shoe, average deceleration keeping to $1.11 / 1.22 \mathrm{~m} / \mathrm{s}^{2}$.

It is to mention that certain parameters, such as jerk, length of the MTB shoe, as well as wear, compatibility requirements etc. must also be considered.

\section{References}

1. C-G. Kang, JMST, 21, 1048-1057 (2007)

2. L. Pugi, M. Malvezzi, S. Papini, S. Tesi, Proc. IMechE, Part F: J. Rail and Rapid Transit, 229, 2, 160-172 (2015)

3. W. Mengling, Z. Lu, W. Xiaodong, Vehicle Engineering, 3, 26-30 (2015)

4. C. Cruceanu, Train braking, in Reliability and Safety in Railway, X. Perpinya (Ed), InTech, 29-74 (2012)

5. Y. Zhu, Adhesion in the wheel-rail contact, Doctoral thesis, Royal Institute of Technology Stockholm (2013)

6. C. Cruceanu, M. Dumitriu, C. Crăciun, MATEC Web of Conf., 112 (2017)

7. C. Cruceanu, C.I. Crăciun, I.C. Cruceanu, Rail Transport-Systems Approach, 87, 3-33, Springer International (2017)

8. A. Nasr, S. Mohammaddi, Proc. IMechE, 224, Part F: JRRT, 523-534 (2010) 